\title{
LOCALIZATION OF THE 'APICAL BODY' IN GUINEA-PIG AND HUMAN SPERMATOZOA WITH PHOSPHOTUNGSTIC ACID
}

\author{
MILDRED GORDON \\ Department of Obstetrics and Gynecology and Department of Biology, \\ Yale University, New Haven, Connecticut, U.S.A.
}

(Received 27th Fanuary 1969)

Recent data on mammalian spermatozoa have revealed that profound changes take place in the acrosome before the spermatozoon penetrates the zona pellucida of the ovum. The plasma membrane and the outer membrane of the acrosome vesiculate, releasing the acrosomal contents (Austin \& Bishop, 1958; Austin, 1963; Hadek, 1963; Piko \& Tyler, 1964; Barros, Bedford, Franklin \& Austin, 1967; Bedford, 1967b). The inner acrosome membrane then becomes the outer ensheathment of the sperm head. Under these circumstances, the contents of the compartment between the inner acrosome membrane and the nucleus may be important for the movement of the spermatozoon through the zona and fusion of spermatozoon and ovum.

Since it resides in the subacrosomal space at the apex of the nucleus, the 'apical body' is in a strategic locus for the approach of the spermatozoon toward the egg. The apical body, however, is a controversial structure since it has been reported in some mammals (Hadek, 1963; Nicander \& Bane, 1966; Bedford, 1967a) but it has not been seen in others (Fawcett \& Ito, 1965). Among the primates, Bedford (1967a) noted a subacrosomal body in the bush baby but it was not present in man.

Because of the enormous development of the guinea-pig acrosome (Fawcett, 1965), this species is particularly favourable for analysis of the organelle and related substructures. An apical body, however, has not been consistently observed in the guinea-pig. It was described as a diffuse mass by Nicander \& Bane (1966) but it was not present in an extensive study by Fawcett (1965).

It was decided in the present study to reinvestigate the apical body in guineapig spermatozoa and spermatids treated en masse with ethanolic phosphotungstic acid (E-PTA). This technique (Gordon \& Bensch, 1968) was chosen for several reasons: (1) intracellular components which are not apparent with osmium tetroxide are stained with E-PTA (Bloom \& Aghajanian, 1968; Gordon \& Bensch, 1968), (2) phosphotungstic acid enhances the tinctorial qualities of the 'post-nuclear cap' (Nicander \& Bane, 1962) which, like the apical body, is in the extra-nuclear region of the sperm head, (3) phosphotungstic acid used after 
fixation in osmium tetroxide revealed densities in the subacrosomal space of some mammalian species (Nicander \& Bane, 1966) and (4) E-PTA stained substructures of flagellar organelles of the guinea-pig spermatozoon which were not present with osmium tetroxide alone (Gordon \& Bensch, 1968).

Guinea-pig spermatozoa, expressed from the cauda epididymidis, were fixed in glutaraldehyde and treated en masse with E-PTA before embedding in plastic (Gordon \& Bensch, 1968). Ejaculated human spermatozoa were also studied with the above procedure. Human spermatozoa were chosen because: (1) the apical body has not been seen in this species when prepared by conventional methods for electron microscopy (Bedford, 1967a); (2) the human acrosome, in contrast to the guinea-pig, is a uniform thin structure and the subacrosomal space is minimal with no apical differentiation. Samples of guinea-pig testis were fixed in glutaraldehyde, refixed in osmium tetroxide and then embedded in plastic both with and without exposure to E-PTA.

In guinea-pig spermatozoa, a dense body was observed which occupied a notch beneath the inner acrosomal membrane (Pl. 1, Fig. 1). In contrast to previous observations (Nicander \& Bane, 1966), it was not amorphous but had a distinct shape and clearly demarcated outlines (PI. 1, Fig. 1). It was triangular in sagittal section and did not fill the subacrosomal space. There was an unstained interval between the limits of the body and the nucleus. Since E-PTA also stained the internal surface of the acrosomal membrane, the membrane itself is indicated in negative relief (Pl. 1, Fig. 1). In the human spermatozoon, a small distinct body was also seen beneath the inner acrosome membrane at the cephalad tip of the nucleus (Pl. 1, Fig. 2). As in the guineapig, it followed the outline of the inner acrosome membrane and was disposed toward the acrosome rather than the nucleus. In both species, scattered densities were apparent in the subacrosomal space at the sides of the nucleus (Pl. 1, Figs. 1 and 2).

An apical body was present in very late spermatids still attached to the testicular epithelium (Pl. 2, Fig. 3). It was not apparent in cells fixed in osmium tetroxide and not treated with E-PTA (Pl. 2, Fig. 4), resembling the results obtained in mature spermatozoa (Fawcett, 1965) with similar techniques.

In terms of acrosome development, the guinea-pig and human spermatozoon are extremes among mammals, since the human has one of the smallest and the guinea-pig one of the largest organelles. The size and shape of the apical body apparently follows the size and development of the acrosome, since it is prominent in the guinea-pig and much smaller, although distinct, in the human.

The present results strongly suggest that the apical body may be a permanent feature of mammalian spermatozoan morphology and therefore a critical structure in the reproductive mechanism. The binding of E-PTA to proteins (Bloom \& Aghajanian, 1968), possibly basic proteins (Winitz \& Greenstein, 1961), suggests that the apical body is proteinaceous, may possess enzymic properties which promote the passage of the spermatozoon through the zona pellucida of the ovum.

This investigation was supported by Ford Foundation Grant 67-560. 


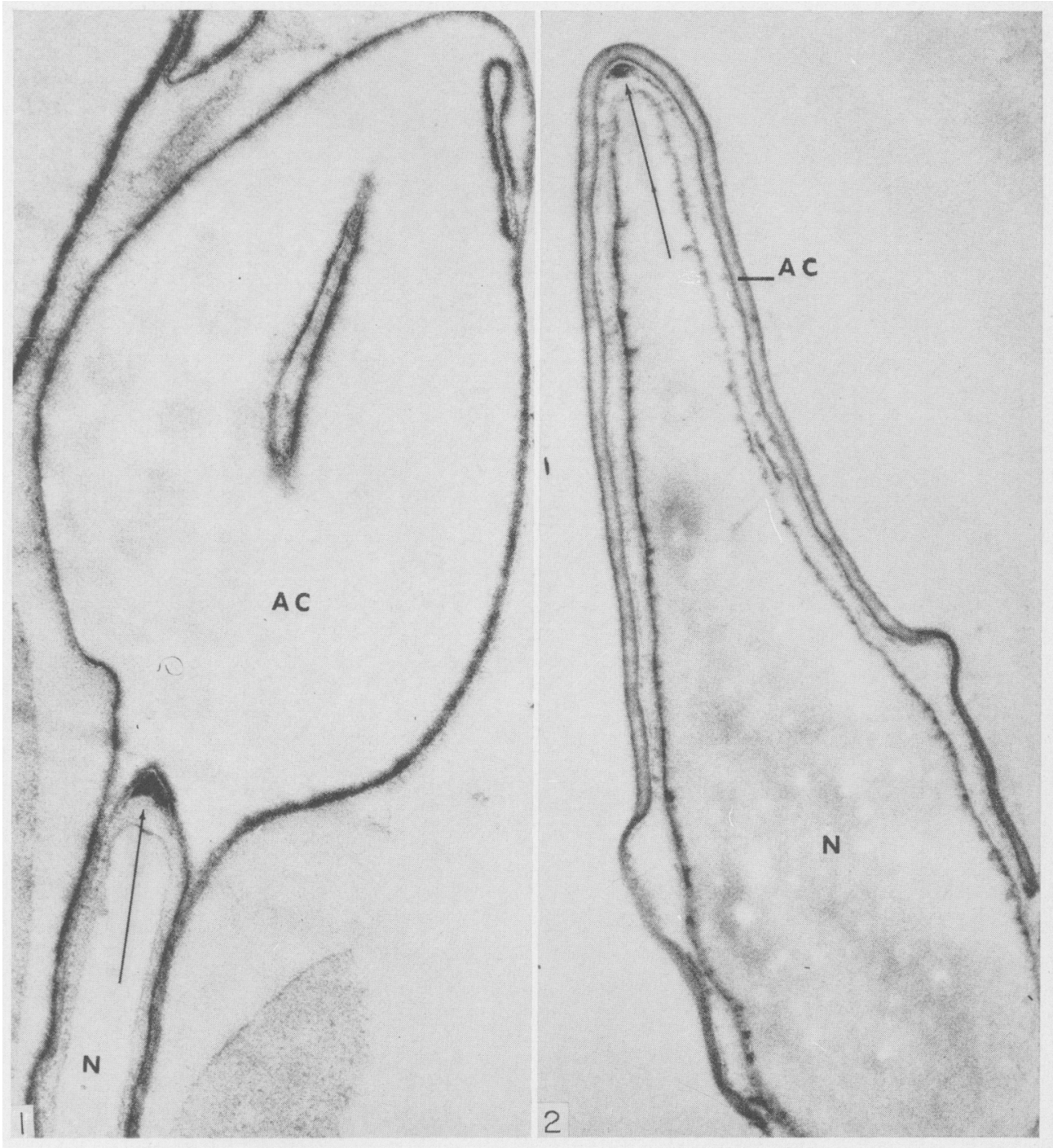

Frg. 1. Epididymal guinea-pig spermatozoon, fixed in glutaraldehyde and treated with E-PTA without fixation in osmium tetroxide. Membranes are not preserved. The acrosome (AC) is stained internally at the periphery. The apical body (arrow) is in the subacrosomal space, closely applied to the acrosome. The inner acrosome membrane appears in negative relief between the apical body and the internal stained layer. The nucleus (N) is not dense. Unstained. $\times 46,250$.

Fig. 2. Head of human spermatozoon, fixed in glutaraldehyde and treated with E-PTA without fixation in osmium tetroxide. The acrosome (AC) is a thin structure. The apical body (arrow) is at the apex of the nucleus $(\mathrm{N})$. The inner acrosome membrane appears in negative relief above the body. Unstained. $\times 52,700$.

(Facing p. 368) 


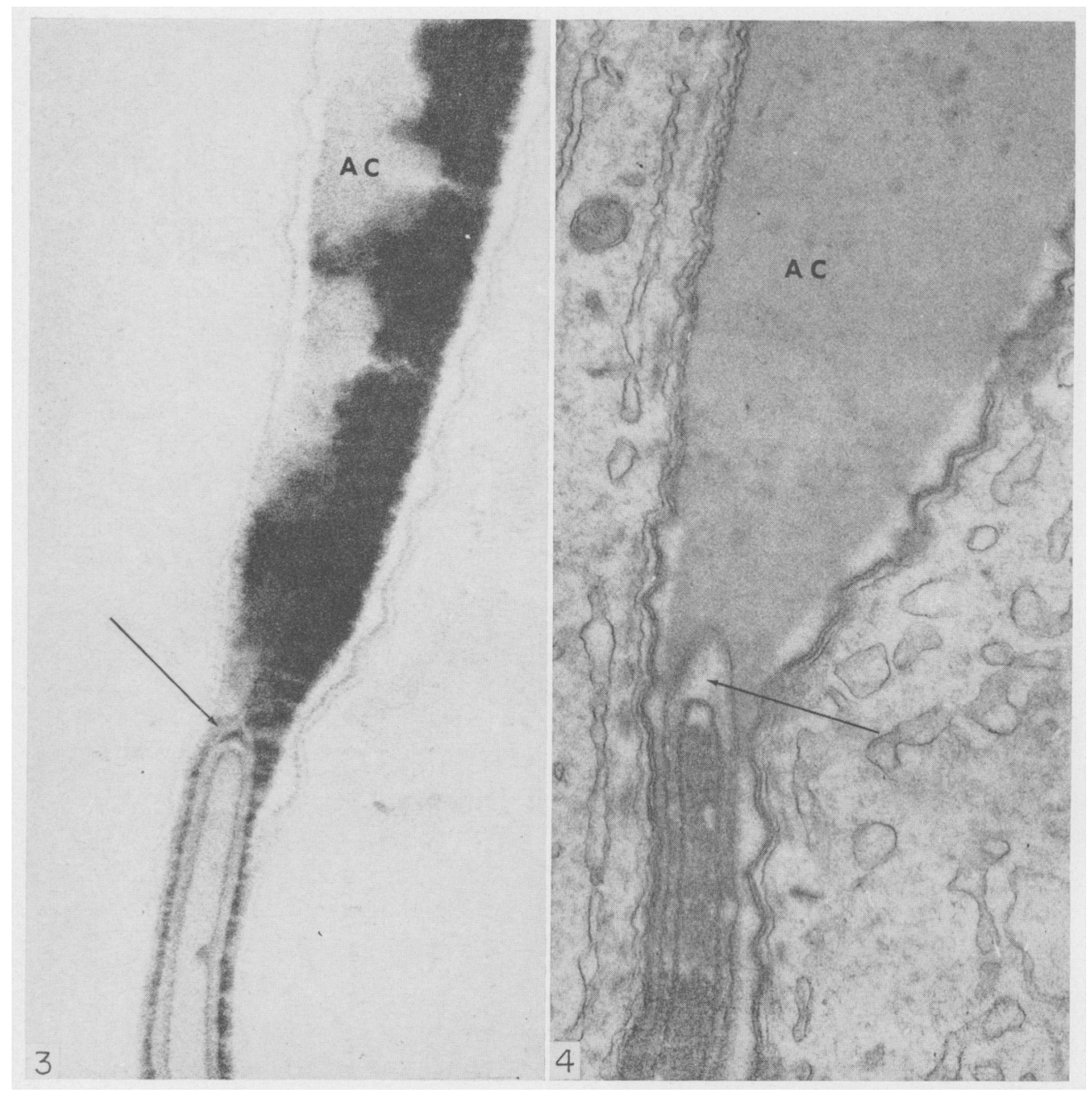

Fig. 3. Late spermatid in the guinea-pig testis. Tissue fixed in glutaraldehyde, refixed in osmium tetroxide and then treated with E-PTA. A triangular apical body (arrow) is present beneath the acrosome $(A C)$. Unstained. $\times 3474$.

Frg. 4. Late spermatid in the guinea-pig testis, fixed in glutaraldehyde and refixed in osmium tetroxide without exposure to E-PTA. Thin plastic section stained with lead. The sub-acrosomal space (arrow) does not show an apical body. A portion of the acrosome $(\mathrm{AC})$ is seen. $\times 3938$. 


\section{REFERENCES}

Austin, C. R. (1963) Acrosome loss from the rabbit spermatozoon in relation to entry into the egg. 7. Reprod. Fert. 6, 313.

Austin, C. R. \& Bishop, M. W. H. (1958) Role of the rodent acrosome and perfortorium in fertilization. Proc. R. Soc. B, 148, 241.

Barros, C. J., Bedford, J. M., Franklin, L. E. \& Austin, C. R. (1967) Membrane vesiculation as a feature of the mammalian acrosome reaction. F. Cell Biol. 34, C1.

BEDFORD, J. M. (1967a) Observations on the fine structure of spermatozoa of the bush baby (Galago senegalensis), the African green monkey (Cercopithecus aethiops) and man. Am. J. Anat. 121, 443.

BEDFORD, J. M. (1967b) Experimental requirement for capacitation and observations on ultrastructural changes in rabbit spermatozoa during fertilization. F. Reprod. Fert. Suppl. 2, 35.

Bloom, F. E. \& Aghajanian, G. K. (1968) Fine structural and cytochemical analysis of the staining of synaptic junctions with phosphotungstic acid. F. Ultrastruct. Res. 22, 361.

FawCETT, D. W. (1965) The anatomy of the mammalian spermatozoon with particular reference to the guinea pig. Z. Zellforsch. mikrosk. Anat. 67, 279.

Fawcetr, D. W. \& Ito, S. (1965) The fine structure of bat spermatozoa. Am. F. Anat. 116, 567.

GorDon, M. \& BENSCH, K. G. (1968) Cytochemical differentiation of the guinea pig sperm flagellum with phosphotungstic acid. F. Ultrastruct. Res. 24, 33.

HADEK, R. (1963) Study on the fine structure of the rabbit sperm head. F. Ultrastruct. Res. 9, 110.

NiCANDER, L. \& BANE, A. (1962) Fine structure of boar spermatozoa. Z. Zellforsch. mikrosk. Anat. 57, 390.

NicANDER, L. \& BANE, A. (1966) Fine structure of the sperm head in some mammals with particular reference to the acrosome and the subacrosomal substance. Z. Zellforsch. mikrosk. Anat. 72, 496.

Piko, L. \& Tyler, A. (1964) Fine structural studies of sperm penetration in the rat. Vth int. Cong. Anim. Reprod., Trento, 2, 372.

Winitz, M. \& Greenstein, J. P., Eds. (1961) The chemistry of the amino acids. Wiley, New York. 